\title{
Retórica e argumentação: contribuições para a educação escolar
}

\section{Rhetoric and argumentation: contributions to school education}

\author{
Helen Silveira Jardim de Oliveira* \\ Renato José de Oliveira**
}

\begin{abstract}
RESUMO
Este artigo pretende investigar as contribuições da retórica e da argumentação para a educação escolar, analisando as nuances existentes entre as relações argumentativas e dialógicas que ocorrem no espaço educacional, especialmente entre professores e alunos. $\mathrm{O}$ texto defende uma educação de cunho argumentativo, fundamentada na racionalidade retórica. Para tanto, valoriza as diversas opiniões dos sujeitos, incentivando-os à interrogatividade, tendo como objetivo chegar a acordos plausíveis, suscetíveis a renovações sempre que necessário. A educação, nessa abordagem, não nega a problematização e acolhe as questões trazidas pelos diferentes auditórios.

Palavras-chave: Argumentação. Nova Retórica. Problematização. Dialogia. Educação escolar.
\end{abstract}

\begin{abstract}
This article aims to investigate the contributions of rhetoric and argumentation to school education, analyzing the nuances that exist between the argumentative and dialogic relations that occur in the education space, especially among teachers and students. The text nourishes education of an argumentative nature, based on the rationality of rhetoric, and promotes the
\end{abstract}

* Colégio Pedro II - Campus São Cristóvão I. Rio de Janeiro, Brasil. Campo de São Cristóvão, nº 177. São Cristóvão. CEP: 20921-440. E-mail: prof_helen@yahoo.com.br. https://orcid. org/0000-0002-3738-9529.

** Universidade Federal do Rio de Janeiro. Rio de Janeiro, Rio de Janeiro, Brasil. Av. Pasteur, nº 250. Urca. CEP: 22290-240. E-mail: rj-oliveira1958@uol.com.br. https://orcid.org/00000002-8071-848X. 
diverse opinions of the subjects, encouraging them to questioning. It has the goal of reaching reasonable agreements, always susceptible to renovation when and where necessary. In this approach, education does not deny questioning and welcomes all issues brought about by different audiences.

Keywords: Argumentation. New rhetoric. Questioning. Dialogic. School education.

\section{Introdução}

À luz da Teoria da Argumentação, também denominada de Nova Retórica, desenvolvida por Perelman e Olbrechts-Tyteca (2005), este artigo pretende analisar um assunto que para nós é caro, importante e que vem ganhando centralidade nos últimos anos: a argumentação e a dialogia na educação. Sendo assim, pretendemos analisar as nuances existentes entre as relações argumentativas e dialógicas que ocorrem no espaço educacional, especialmente entre professores e alunos, observando como ocorre tal construção.

Existe um leque de definições de argumentação e dialogia; todavia, em linhas gerais, consideramos a argumentação um processo que "visa à adesão dos espíritos e, por isso mesmo, pressupõe a existência de um contato intelectual" (PERELMAN; OLBRECHTS-TYTECA, 2005, p. 16). Ressaltamos que a palavra "espíritos" é empregada no sentido de mentes, de sorte que a argumentação objetiva à adesão destas a uma tese apresentada.

E a dialogia? Consiste em um processo de interação, ou seja, no contato intelectual entre diferentes indivíduos por intermédio da expressão de discursos orais ou escritos em que não há, necessariamente, a persuasão como finalidade. A dialogia envolve trocas diversas, dentre as quais: informações, conhecimentos, saberes e experiências.

Segundo Oliveira (2014, p. 456): "O recurso à argumentação se torna necessário quando os interlocutores não chegam imediatamente ao consenso". E decerto, pensar em educação, mais precisamente no espaço escolar, é admitir a existência constante de uma multiplicidade de opiniões, da presença de conflitos e também de divergências. Mas é óbvio que na escola também há momentos de consensos e convergências, pois, se não fossem por eles, tal instituição não se sustentaria.

Sobre o tema, Meyer $(2002,2007)$ considera que visões diferenciadas acerca de um assunto, questão ou problema, originam uma distância que pode ser ampliada ou reduzida conforme o desenvolvimento da argumentação. Isto 
é, a relação argumentativa, em muitos momentos, será permeada por opiniões conflitantes e divergentes entre orador e auditório. "Falar, assim como escrever, equivaleria a suscitar uma questão e, portanto, esses atos trazem sempre implícitas as perguntas que lhes correspondem" (MEYER, 2007, p. 9).

Sobre a categoria orador e auditório, Perelman e Olbrechts-Tyteca (2005, p. 22, grifo dos autores) colocam que é "[...] preferível definir o auditório como o conjunto daqueles que o orador quer influenciar com sua argumentação" e mais "[...] ao auditório cabe o papel principal para determinar a qualidade da argumentação e o comportamento dos oradores" (PERELMAN; OLBRECHTS-TYTECA, 2005, p. 27). Vale ressaltar que o orador pode persuadir oralmente ou por escrito, salienta Perelman (2004).

Nessa linha de raciocínio, também é nosso objetivo defender uma proposta de educação de cunho argumentativo que, em linhas gerais, fundamenta-se na racionalidade argumentativa - também denominada de retórica - e que deve valorizar as diversas opiniões dos sujeitos e incentivar a interrogatividade a fim de chegar a acordos plausíveis, sendo passíveis de renovações sempre que necessário. Uma educação argumentativa é aquela que não nega a problematização e que acolhe as questões trazidas pelos diferentes auditórios.

Consideramos que pensar numa educação de cunho argumentativo ou de abordagem argumentativa não é tarefa fácil, pois estamos vivendo em uma sociedade em que há cada vez menos disposição para ouvir o outro, considerar seus interesses, suas necessidades, inquietações e questões. Também observamos indivíduos que estão vivenciando um completo desânimo por não haver acolhimento às suas colocações. Está havendo, gradativamente, um momento de esfriamento das relações pessoais, ou seja, percebemos que há um aumento significativo da solidão e do egocentrismo. Esse pano de fundo certamente gera influências no cenário escolar que inclusive atuam, em alguns momentos, reproduzindo tais ações sociais. Entendemos que, em alguma medida, estamos vivendo um dilema ético.

A valorização das diferentes vozes presentes na educação também tem sido outro desafio. Apesar do cenário fértil para diferentes discussões, ainda é uma tarefa árdua buscar uma conciliação entre diferentes perspectivas e visões, segundo nosso pensamento, pelo fato de estarmos acostumados com a polarização e com o binarismo. Apropriando-nos do título de uma das obras de Cecília Meireles (2014), seria uma espécie de Ou isto ou aquilo. Certamente se não buscarmos um meio termo entre os extremos, uma negociação de distâncias, o fôlego de vida da escola irá decrescer até sua existência não ter mais sentido.

Apesar de muitas vezes, como professores, sentirmos um desânimo em relação às discussões pedagógicas que ocorrem no seio da escola, por constatarmos que algumas delas nos levam a lugar nenhum, consideramos que uma das 
formas de superarmos o autoritarismo e a verticalização das decisões seja pelo viés da argumentação. Não podemos abrir mão de problematizarmos nem entre o grupo de docentes, nem com nossos alunos, pois é através desse processo que conseguimos trilhar, em inúmeras situações, novos caminhos em relação a uma determinada questão, renovando as reflexões - ou promovendo novas! - sobre um determinado assunto. Problematizar também é uma etapa importante no processo de aprendizagem tanto para docentes quantos para discentes, já que o aprendizado decorre do confronto entre convicções e percepções acerca de diferentes assuntos.

Em vista disso, não há receitas a serem seguidas na educação; o que existem são experiências construídas a cada dia por meio de diversas e complexas interações em ambientes argumentativos distintos. Experiências satisfatórias e significativas oriundas das argumentações, de diálogos e de problematizações, devem ser compartilhadas servindo de exemplo, subsídio e inspiração a outros docentes.

\section{As definições, funções e origens da retórica clássica}

Discorrer a respeito da argumentação e dialogia nos remete, em primeiro lugar, a refletirmos sobre a retórica e a dialética na perspectiva grega, pois elas são as fontes teóricas iniciais relativas a tais categorias. Sendo assim, iniciaremos realizando uma breve trajetória histórico-filosófica da retórica clássica, já que ela consiste no ponto de partida da concepção dos autores que tratam da Nova Retórica (PERELMAN; OLBRECHTS-TYTECA, 2005) e da Problematologia (MEYER, 2002).

Para Perelman (2004, p. 177):

A retórica clássica, a arte de bem falar, ou seja, a arte de falar (ou escrever) de modo persuasivo se propunha estudar os meios discursivos de ação sobre um auditório, com o intuito de conquistar ou aumentar sua adesão às teses que se apresentavam ao seu assentimento.

Muitas vezes ao nos reportarmos à retórica, à argumentação e à dialogia, enfatizamos a oralidade e esquecemo-nos dos textos que também podem ser considerados valiosos instrumentos persuasivos. 
Reboul (2004, p. XIV) também corrobora essa visão agregando, no entanto, um novo ingrediente: o discurso.

Eis, pois, a definição que propomos: retórica é a arte de persuadir pelo discurso. Por discurso entendemos toda produção verbal, escrita ou oral, constituída por uma frase ou por uma sequência de frases, que tenha começo e fim e apresente certa unidade de sentido.

O autor distingue discursos retóricos de não retóricos. Os retóricos seriam aqueles cujo objetivo é a persuasão. A persuasão, com base em Reboul (2004), seria a capacidade de fazer o outro crer em algo ou em alguma coisa. Se a retórica tem como alvo principal a persuasão, a preocupação com o auditório é fundamental, pois é ele quem irá balizar os argumentos apresentados.

Ressaltamos que embora não haja uma área do conhecimento nos currículos do Brasil que vise ao ensino da retórica especificamente, ela se faz presente nas aulas, estando "diluída" nas disciplinas escolares e em muitas estratégias pedagógicas, como, por exemplo, no júri simulado, na elaboração de uma redação ou na exposição oral de um trabalho. "A retórica permaneceu, só que desarticulada, privada de sua unidade interna e de sua coerência. Em todo caso, os professores, quase sempre sem saberem, fazem retórica" (REBOUL, 2004, p. XXII).

As origens da retórica remontam à Sicília grega por volta de 465 a.C.; como não existiam advogados, era necessário instrumentalizar os litigantes para que eles pudessem defender suas causas; todavia, a retórica não atendeu apenas a uma demanda social de cunho jurídico, tendo servido, também, à literatura, à filosofia e ao ensino (REBOUL, 2004).

Em relação ao ensino, existiam professores itinerantes de eloquência e filosofia, muito bem remunerados, denominados de sofistas. Podemos considerar que os sofistas foram os primeiros pedagogos e sua função era preparar os jovens para o exercício da vida política, como, por exemplo, terem um desempenho satisfatório nas assembleias de cidadãos.

Os sofistas utilizavam a relatividade das verdades, o que contrariava os pensamentos socrático e platônico que consideravam a unicidade da verdade. Tal relativização consistia em deixar o interlocutor perplexo, sem réplica, tendo por maior objetivo vencer, valendo-se por vezes de uma falsa aparência lógica. Para Reboul (2004, p. 9), isso se dava "Certamente porque o mundo do sofista é um mundo sem verdade, um mundo sem realidade objetiva, capaz de criar o consenso de todos os espíritos $[\ldots . .$. ". 
É preciso salientar, entretanto, que nem toda a sofística pode ser resumida a essa observação, como salienta Kerferd (1999). Não obstante, a tradição predominante na filosofia ainda tem Platão como principal referência, já que ele foi um dos filósofos mais críticos dos sofistas, considerando a retórica como sendo uma falsa dialética. A boa retórica seria a dialética, pois essa levaria ao conhecimento pelo viés do questionamento, modelo inspirado em seu mestre, Sócrates. Aristóteles, discípulo de Platão, não compartilhava da mesma visão sobre a retórica; porém, a respeito dos sofistas, também era um árduo crítico, tanto que se propôs a analisar os diferentes tipos de sofisma, revelando-os como mentirosos, no seu tratado Refutações Sofísticas ${ }^{1}$.

Não obstante, podemos dizer com base em Reboul (2004), que a retórica teve prestígio não somente no período grego, mas também durante o império romano, provavelmente por conta da constante presença da cultura grega. $\mathrm{O}$ direito era essencial para a unificação de Roma; logo, a retórica era de grande valia, amplamente utilizada e considerada essencial na educação antiga - Cícero, Quintiliano e Agostinho foram grandes mestres - e também ao longo da Idade Média.

\section{Dialética e retórica: as visões platônica e aristotélica}

Falar sobre retórica implica, também, mergulharmos teoricamente na dialética, visto que ambos os conceitos têm estrita relação. Segundo o Dicionário de Filosofia, de Abbagnano (2007), a palavra dialética deriva de diálogo, não apresentando significado unívoco na Filosofia. Destaca, então, quatro definições fundamentais relativas à dialética: método da divisão, lógica do provável, lógica e síntese dos opostos. Dentre elas, as que mais nos interessam são a segunda e a terceira, pois estão ligadas ao pensamento de Platão e de Aristóteles, os quais iremos analisar com maior profundidade.

Para esses dois filósofos, retórica e dialética têm propósitos diferenciados. Segundo Platão, a retórica é um engodo e só se presta a ludibriar o ouvinte; portanto, ele não aceita que a retórica seja considerada uma arte, pois despreza o verdadeiro. De acordo com Carrilho (2002), Platão marginalizou a retórica, entre outras razões, em decorrência da ação dos sofistas na educação dos jovens na sociedade grega, conforme comentamos na seção anterior. A visão platônica

1 Refutações Sofísticas é o sexto texto do Organon, conjunto de seis textos que Aristóteles dedicou à lógica formal. 
sobre a dialética é inspirada em Sócrates, que, por meio de argumentos fundamentados, lógicos e racionais, entendia ser o diálogo entre as partes uma forma de alcançar a verdade.

Aristóteles concebe a dialética de uma forma diferente. Para ele, esta não buscaria a verdade absoluta, mas o provável (endoxon), o verossímil (eikos), quer dizer, "a força" de verdade, o conjunto das opiniões aceitas. Sendo assim, a dialética utilizaria um silogismo diferente, que seria justamente o oposto do silogismo demonstrativo. O silogismo demonstrativo, utilizado na matemática, por exemplo, parte de premissas para se chegar a uma conclusão válida, irrefutável: a dedução. Já o silogismo dialético envolve um raciocínio que parte do provável, de premissas que não geram conclusões verdadeiras, mas plausíveis.

A dialética poderia ser considerada uma esgrima entre os interlocutores, uma competição verbal, um jogo cujo objetivo seria aprisionar o rival em contradições levando-o ao silêncio. Não havia preocupação com o tempo e nem o compromisso com a persuasão de um auditório. "A dialética de Aristóteles é apenas a arte do diálogo ordenado" (REBOUL, 2004, p. 28). Sendo assim, era necessário utilizar as regras oriundas da lógica de modo coerente e adequado. Podemos dizer que Aristóteles deu nova vida à retórica, reabilitando-a, colocando-a num lugar de destaque e concebendo-a como

[...] a arte de defender-se argumentando em situações nas quais a demonstração não é possível, o que a obriga a passar por "noções comuns", que não são opiniões vulgares, mas aquilo que cada um pode encontrar por seu bom senso, em domínios nos quais nada seria menos científico (REBOUL, 2004, p. 27).

O sistema retórico aristotélico é rico e denso, sendo assim, realizaremos um recorte enfocando alguns de seus aspectos. São identificados, por exemplo, três gêneros do discurso: o judiciário, o deliberativo ou político e o epidíctico porque haveria três tipos de auditório. De forma geral, o discurso judiciário se propõe a acusar ou defender (relacionado ao passado), o deliberativo consiste em aconselhar ou desaconselhar (relacionado ao futuro) e o epidíctico se destina à censura ou ao louvor de alguém ou de alguma categoria (relacionado ao presente).

Aristóteles também concebe três dimensões essenciais da retórica. Segundo Carrilho (2002, p. 50, grifo do autor), sua grande contribuição foi justamente integrá-las: "Quem fala? Qual é o argumento apresentado? A quem se dirige? Ou, dito de outro modo, o ethos, o logos e o pathos". Oliveira (2016) esclarece-nos de modo claro e objetivo o que seria cada uma dessas partes: 
O ethos diz respeito a quem profere o discurso, ou seja, ao orador. Como ele se apresenta? Que traços de personalidade e de caráter exibe? Como se comporta em público: é calmo ou ansioso, arrogante ou humilde, claro ou obscuro em seus pronunciamentos? O logos, por sua vez, é a própria racionalidade presente no discurso: que argumentos sustentam o que é dito? Como se concatenam? O que pretendem mostrar? Finalmente o pathos se vincula ao auditório, ou seja, ao conjunto dos que travam contato com o discurso e, a partir dele, aderem ou não às teses apresentadas. De que maneira esse auditório reage? Quais são suas disposições, seus valores, interesses, etc.? (OLIVEIRA, 2016, p. 12, grifo do autor).

Mesmo com a grande contribuição aristotélica, após a queda do império romano, a retórica foi perdendo importância (em algumas sociedades ela chegou a ser banida dos currículos escolares como, por exemplo, na França) e seus estudos foram minimizados, ainda que ela fosse praticada. Nesse período, ela viveu um período de esquecimento e obscurantismo.

\section{A Nova Retórica, o Tratado da argumentação e algumas articulações com a educação}

Podemos dizer que aconteceram alguns retornos cíclicos da retórica; contudo, apenas no século XX houve um movimento denominado de "virada retórica", que consistiu na sua retomada como objeto privilegiado de estudo por alguns teóricos e pesquisadores, dentre os quais destacamos Chaïm Perelman e sua assistente de pesquisa, Lucie Olbrechts-Tyteca.

Perelman revitaliza e reformula certos aspectos fundamentais da razão grega relacionando-os a algumas ideias provenientes da sua formação em Direito e em Lógica. No ano de $1958^{2}$, ele escreve com Olbrechts-Tyteca o Tratado da argumentação, obra de referência na qual os fundamentos filosóficos da teoria da argumentação ou Nova Retórica são apresentados. E por que Nova Retórica? Os autores tinham como objetivo estudar a lógica dos juízos de valor, buscando outra forma de racionalidade para tratar dos valores porque esses não seriam suscetíveis a uma análise lógica, racional. Nessa trajetória, perceberam que a racionalidade por eles buscada já havia sido tratada outrora pela retórica clás-

2 A primeira edição brasileira foi lançada no ano de 1996. 
sica grega, mais especificamente por Aristóteles. Esse tipo de raciocínio opera utilizando premissas prováveis, resultantes do acordo entre orador e auditório.

Sendo assim, não existe o verdadeiro ou o falso no plano argumentativo, como ocorre na lógica formal, mas, sim, a verossimilhança, dado que as opiniões são valorizadas, e a força delas é que irá conduzir o auditório para uma ou outra tese. De outra maneira, no momento de exposição dos argumentos, o que tiver mais força persuasiva conduzirá o auditório para uma "verdade" ou, melhor dizendo, para um acordo provisório. Provisório porque em outro momento o mesmo auditório poderá ponderar de maneira diferente, dependendo dos condicionantes da argumentação. Considerando, portanto, a retórica um importante instrumento persuasivo, Perelman e Olbrechts-Tyteca optaram por ressignificar a abordagem aristotélica, denominando-a de Nova Retórica.

Ressaltamos que os referidos autores não se dedicaram à articulação da sua teoria com a Educação Escolar, mas com os processos educativos de forma abrangente. Assim sendo, discutem a respeito da diferença entre o discurso utilizado na educação e na propaganda. Eis um fragmento:

Enquanto o propagandista deve granjear, previamente, a audiência de seu público, o educador foi encarregado por uma comunidade de tornar-se o porta-voz dos valores reconhecidos por ela e, como tal, usufrui um prestígio devido a suas funções. (PERELMAN; OLBRECHTS-TYTECA, 2005, p. 58).

A citação considera que o educador não precisa se preocupar em persuadir seu auditório de alunos por conta da confiança que esses teriam em relação a ele, isto é, devido à autoridade conferida aos docentes. Sobre isso, Perelman e Olbrechts-Tyteca (2005, p. 347) observam que "[...] existe uma série de argumentos cujo alcance é totalmente condicionado pelo prestígio. A palavra de honra, dada por alguém como única prova de asserção, dependerá da opinião que se tem dessa pessoa [...]". Oliveira (2011b, p. 32) complementa: "Certos tipos de argumentos se valem do prestígio do orador, invocando sua autoridade moral e/ou intelectual para subsidiar determinada tese".

Concordamos que, em alguma medida, essa confiança absoluta pode ocorrer; conquanto, estando sob a égide de uma educação que incentiva a crítica e a autonomia dos alunos e também pensando que os discentes hoje pertencem a um momento histórico, social e cultural distinto, constatamos que pode haver desconfiança por parte dos alunos acerca dos conhecimentos trazidos pelo professor. Vale ressaltar que não entendemos a desconfiança e a dúvida como 
desrespeito, mas como uma etapa importante relacionada ao processo de construção e aquisição de saberes. Reconhecemos, desse modo, que as concepções sobre educação na época em que o Tratado foi escrito diferem da atualidade, uma vez que a função docente e a educação não são atemporais e possuem marcas históricas e socioculturais peculiares.

Ao admitirem que os educadores são os porta-vozes dos valores socialmente reconhecidos, Perelman e Olbrechts-Tyteca não se detiveram a discutir as muitas situações em que há divergências entre oradores e auditórios e, por isso, faz-se necessário negociar as distâncias sobre diferentes assuntos e questões. Percebemos que em inúmeros casos, o docente pode ser porta-voz dos seus próprios interesses ou dos interesses da instituição de ensino e não do interesse de quem os ouve, no caso, seus alunos. Assim como a sociedade é heterogênea, os auditórios também o são. Além de serem diversos, variam sobremaneira na quantidade e na extensão, inclusive, julgam uns aos outros (PERELMAN; OLBRECHTS-TYTECA, 2005).

Segundo o Tratado, o orador tenta persuadir seu auditório levando-o a aderir ao argumento que propõe. Para tal, deve buscar conhecer o(s) auditório(s) e adaptar sua argumentação a ele(s). Para conseguir adesão, o orador pode se valer de múltiplos argumentos na interação com o(s) auditório(s); todavia, a força deles é que poderá propiciar o propósito almejado. Além disso, o conjunto de pessoas para as quais queremos nos dirigir é muito variável e esse contato intelectual pode parecer supérfluo ou pouco desejável em relação a alguns indivíduos. Isso significa que não temos o total controle quantitativo nem qualitativo de nossa argumentação e que também nem sempre estamos interessados ou predispostos a iniciar uma argumentação com determinado auditório.

Podemos ver essa situação claramente na educação. Muitas vezes, nossos alunos não estão interessados pelos debates que desejamos realizar em aula e tampouco nas aulas em si, o que nos leva a culpá-los. Será, contudo, que como oradores estamos usando as melhores ferramentas para persuadir nosso auditório? Será que nossas estratégias são as mais adequadas? Será que conhecemos os estudantes o suficiente para alcançar sua adesão? Consideramos tais perguntas de cunho reflexivo de suma importância para a boa condução do processo educativo.

Ponderamos, outrossim, que em diferentes momentos a função de orador não cabe apenas a reitores, diretores, coordenadores, orientadores ou a pessoas que exercem algum cargo de chefia na escola. Falando especificamente da sala de aula, essa função também não é exclusiva do professor! Alunos, de qualquer idade, devem ser estimulados a exercê-la com ética, respeito e responsabilidade. Também estendemos o compartilhamento do papel de orador aos técnicos e aos funcionários, cujas funções são cruciais para que outras ações, não necessaria- 
mente de cunho pedagógico, sejam realizadas com êxito. Poder argumentar é um direito de todos e deve ser acolhido e respeitado pelos diferentes auditórios.

Constatamos que, na grande maioria das situações, há um tipo de "supremacia de oradores", configurando uma verticalização/hierarquização das relações e dos argumentos. É como se as vozes das instituições e as dos representantes dela - os que possuem cargos "superiores" - fossem mais persuasivas que as dos professores e, as destes, mais persuasivas que as dos alunos. Isso se configura em um modelo que, segundo a nossa concepção, não é adequado, pois entendemos que a escola deve ser um espaço de interlocução. A monopolização das falas - seja de um professor ou grupo de professores ou de um aluno, ou grupo de alunos - também deve ser combatida para que aconteça um processo argumentativo genuinamente democrático.

Os autores do Tratado apontam um viés interessante que nos faz considerar que a relação orador/auditório não deve ser rígida, muito menos inflexível: "Para argumentar, é preciso ter apreço pela adesão do interlocutor, pelo seu consentimento, pela sua participação mental" (PERELMAN; OLBRECHTS-TYTECA, 2005 , p. 18). De outro modo, o orador deve valorizar a opinião, o argumento do auditório. O auditório deve ter voz. Se não a tem e sua argumentação não é valorizada, esse processo é autoritário e não argumentativo.

Para nós, deve haver um esforço para refletirmos sobre e até mesmo incentivarmos a horizontalidade do diálogo no espaço educacional. Tal perspectiva faz-nos compreender a dinâmica escolar de um modo mais aberto, respeitoso e acolhedor. Nesse espaço os sujeitos podem apresentar seus argumentos e também refutar os que lhes forem colocados quando não atenderem às suas expectativas.

Quando falamos em abrir espaço para diferentes vozes e do incentivo ao diálogo, logo nos vêm à mente o tema diversidade (de gênero, de etnias, de religiões etc.), que tem ocupado um locus privilegiado nos debates escolares e políticos. A experiência profissional de um de nós como professor e coordenador pedagógico há vários anos tem mostrado uma incompatibilidade (incoerência) entre o que se diz e o que se faz, visto que, apesar de haver ampla defesa da convivência pacífica entre pessoas, concepções, escolhas e culturas diferentes há uma tendência - natural de qualquer ser humano - a aderir a opiniões e formas de conduta admitidas como condizentes. Valendo-nos das categorias do Tratado, dizemos que o indivíduo adere ao que converge com a sua imagem de auditório universal.

Defendemos que o "lugar" da diversidade não é o da aceitação e o da tolerância, muito menos o da concordância, mas o do respeito. Se dizemos que aceitamos ou toleramos alguém ou alguma situação, em alguma medida, já criamos um distanciamento e uma hierarquia entre nós e o outro. Para estabelecermos um acordo, que é diferente de concordância, temos que procurar 
minimizar as distâncias que nos separam do outro e para isso precisamos ceder, não de modo acrítico, mas reflexivo!

Na escola e na sociedade como um todo, precisamos de menos aceitação, tolerância ou concordância e de mais acolhimento e respeitabilidade. Devemos argumentar em prol da reciprocidade que procura "aplicar o mesmo tratamento a duas situações correspondentes." (PERELMAN; OLBRECHTS-TYTECA, 2005, p. 250), evocando a regra de justiça, que "requer a aplicação de um tratamento idêntico a seres ou a situações que são integrados numa mesma categoria" (PERELMAN; OLBRECHTS-TYTECA, 2005, p. 248).

Perelman e Olbrechts-Tyteca (2005) em nenhum momento se valem das palavras supracitadas - aceitação, tolerância, concordância, acolhimento, respeito - eles falam de acordo. Defendem que a argumentação não deve ser coerciva e que, para que ela se inicie, deve existir um acordo inicial, ou melhor, condições prévias capazes de permitir que o processo argumentativo se desenvolva. Como princípio geral para haver acordo prévio, Lemgruber e Oliveira (2011, p. 43) destacam a "disposição para ouvir o outro".

Em sala de aula, consideramos que alunos devam ser ouvidos por alunos e professores, e que professores devam ser ouvidos pelos alunos. Apesar desse princípio já ter sido acolhido na educação, sabemos que não há unanimidade nas práticas educativas. Percebemos que, na sociedade atual, tem havido um recrudescimento da impaciência, do desrespeito e da violência propriamente dita entre docentes e discentes, conforme divulgado nas diferentes mídias.

\section{O pensamento problematológico de Michel Meyer na educação}

Assim como Perelman, o objeto privilegiado de estudo de Meyer não é a educação, mas a retórica. Sua abordagem acerca da argumentação foi denominada de Problematologia, tanto que sua obra de referência recebe esse nome. Tanto a retórica quanto a Problematologia têm contribuições profícuas para a educação, ressaltando que uma não é superior a outra, mas, sim, complementares. Enquanto Perelman e Olbrechts-Tyteca enfatizam o desejo do orador em persuadir seu auditório, Meyer preconiza que existe uma distância entre orador e auditório que pode ser ampliada ou minimizada, por isso, para ele [...] A "retórica é a negociação da distância entre os indivíduos a propósito de uma questão", ou seja, de algo que está em questão porque funciona como questão (2002, p. 268, grifo do autor). Os enfoques são diferentes, mas dialogam. Mesmo porque, para ter êxito na persuasão, orador e auditório devem procurar encurtar a distância através da pluralidade e assertividade dos argumentos. 
Meyer reconhece a multiplicidade de aspectos que permeia as diferenças existentes entre orador e auditório. Logo, podemos depreender que a negociação de distâncias pode ser considerada um processo que é simultaneamente heterogêneo, singular e árduo. Heterogêneo pelo fato de orador e auditório serem pessoas com características distintas. Singular porque não ocorre da mesma maneira entre indivíduos, sendo um momento ímpar. E árduo, pelo fato de haver, muitas vezes, desgaste pessoal nos momentos de debate e discussão.

Encontramos exemplos disso na Educação Musical e na Matemática. Na Educação Musical se faz presente em atividades que envolvem a percepção e a apreciação musical. O professor pode oferecer uma música a ser apreciada e desejar que o aluno perceba determinados elementos; contudo, o aluno pode não perceber exatamente o que o docente espera, mas aponta outras características e tece considerações que também são plausíveis. Na Matemática, esse confronto de respostas ocorre com frequência durante a resolução de situações-problema. Um professor pode desejar que o aluno solucione a questão seguindo o método mais prático, ou validando apenas uma única forma de resolução, mas o aluno pode utilizar outros caminhos que também chegam à resposta correta.

Meyer também nos apresenta o tríptico problematológico (ou tríptico argumentativo) que consiste em uma tripla forma de questionamento: quanto ao sujeito, ao predicado e a quem profere o discurso (enunciador). Reportando-nos às suas próprias palavras, "há uma argumentação baseada nos factos, na sua qualificação e no direito do orador a argumentar" (MEYER, 2002, p. 275). Oliveira (2011a, p. 98) acrescenta que "a interrogatividade em destaque conjuga os aspectos conjectural (relativo aos fatos), qualificativo (relativo ao predicado) e normativo (relativo ao que se pede ou quer), integrando ethos, logos e pathos"

Eis um exemplo que contempla os aspectos apontados anteriormente: uma instituição acusa um grupo de alunos de ter burlado algumas regras combinadas pela turma nas aulas de música, considerando-os, assim, indisciplinados e merecedores de sanção. Fundamentados em Meyer (2002) e Oliveira (2008, 2011a) podemos analisar a situação de três maneiras:

a) não foi o referido grupo de alunos que realizou tal ação, ou a mesma não existiu. Nesse caso, houve um questionamento em relação à natureza do fato (o que ocorreu não é "verdade"). Também podemos dizer que existiu um questionamento quanto à identidade (x não é $\mathrm{y}$ );

b) foi o grupo de alunos acusados que burlou as regras combinadas pela turma, mas isso não significa que os mesmos sejam indisciplinados. Nesse caso, questiona-se a qualificação dada ao predicado. O grupo de alunos não é necessariamente indisciplinado, pode ter sido somente desatento;

c) a professora de música desse grupo de alunos não tem autoridade moral para julgar o comportamento dos alunos, porque ela própria desres- 
peita também algumas regras combinadas com a turma. Nesse caso, questiona-se a norma, a decisão tomada de punir os alunos, já que a professora costuma não honrar o que acordara.

Percebemos que as premissas adotadas e as respostas apresentadas possuem uma "diferença problematológica", ou seja, em termos argumentativos há uma diferença entre quem questiona e quem responde. Além de termos "n" possibilidades de resposta(s), essa(s) resposta(s) podem não encerrar uma discussão, aliás, podem ter um "teor apocrítico" reduzido, já que a resposta apocrítica é aquela que anula (encerra) o questionamento. Toda resposta que não seja estritamente objetiva, remete a novas questões e pode propiciar uma problematização constante. Em diversos momentos, notamos que os docentes se valem do argumento de autoridade para encerrar uma discussão, inibindo a continuação do questionamento dos alunos. Sabemos que às vezes isso é necessário, mas o abuso da postura apocrítica acaba por prejudicar uma educação de cunho argumentativo.

Meyer aponta três formas arquetípicas de questionamento; contudo, podemos afirmar que há inúmeras maneiras de se interrogar, até porque cada indivíduo tem uma forma diferente de interpretar um enunciado ou um fato. Podemos dizer que esse é o caráter hermenêutico da negociação de distâncias.

É importante, todavia, encerrar as discussões, tendo em vista que elas podem ser reabertas e retomadas, possibilitando assim que novos acordos sejam estabelecidos. Discussões que não se encerram podem gerar descrédito, desconfiança e mal-estar. Acreditamos que na educação não devam existir acordos eternos e atemporais, mas, sim, que o meio termo e a razoabilidade possam balizar as discussões. Nessa perspectiva, em sala de aula, o professor pode atuar como mediador de conflitos e a escola pode ser um espaço de interlocução.

Julgamos, portanto, que os estudos de Meyer são pertinentes à educação e podem gerar reflexões relevantes, pois acreditamos que o desejo dos docentes é de se aproximar dos alunos e negociar as inúmeras questões existentes na escola e em sala de aula. Negociar não é fácil, mas, a nosso ver, é um elemento essencial no espaço escolar. É um desafio à ação docente e uma importante ferramenta ao nosso dispor. 


\section{Considerações finais}

Nosso intento foi apresentar algumas contribuições da retórica e da teoria da argumentação ao processo educativo por considerar que estamos vivenciando um momento tenso e delicado em relação ao diálogo e à argumentação entre os diferentes auditórios que convivem nas instituições escolares. No cenário escolar, muito tem se falado sobre a importância desses dois conceitos; entretanto, consideramos que a compreensão sobre eles ainda é limitada.

Dialogar e argumentar não significa "não sistematizar" algumas decisões. Muitas vezes temos banalizado e não dado crédito aos debates por considerar que implicam em uma situação confusa e desorganizada. Não é qualquer troca de palavras que pode ser pensada como uma ação dialógica ou um processo argumentativo. Ambos consistem em uma situação em que há uma interação respeitosa de argumentos, visando a algum entendimento, a um acordo.

A perspectiva dialógica e argumentativa não é unilateral. Caso o auditório não tenha o interesse de participar de alguma discussão, corre-se o risco de esse momento ser teatral e artificial, pois, na realidade, as distâncias que separam orador e auditório permanecem as mesmas, podendo até aumentar. Ao pensar sobre situações de sala de aula e ao exercer o papel de orador, o professor deve observar essa e outras questões, até porque a tomada de consciência a respeito das qualidades e das limitações pessoais e as dos auditórios é indubitavelmente um diferencial no desenvolvimento da argumentação.

Também cabe ao docente não permitir que a heterogeneidade do auditório se torne um problema - gerando ou reforçando incompatibilidades - e ter a habilidade e a sensibilidade para transformar as diferenças em aliadas, de modo que haja complementaridade e troca de experiências satisfatórias entre ele e os auditórios e também entre os próprios auditórios.

Consideramos que a negociação de distâncias pode se constituir num caminho pertinente e promissor que será aperfeiçoado no seu constante exercício. Ela pode acarretar soluções plausíveis - razoáveis - para os diversos conflitos, mas infelizmente não impede que uma discussão possa ser encerrada utilizando a violência. Outra limitação dela é que em inúmeras situações do dia a dia escolar, temos que tomar decisões que não podem esperar. Sendo assim, o sucesso da negociação também depende do tempo disponível para o diálogo e da aptidão de quem a utiliza. Ressaltamos que ela é um meio e não a redenção! Que o desejo de estimular práticas dialógicas, argumentativas e problematizadoras na educação seja maior que o desânimo e a falta de esperança. 


\section{REFERÊNCIAS}

ABBAGnANO, N. Dicionário de Filosofia. 5. ed. São Paulo: Martins Fontes, 2007.

CARRILHO, M. M. Aristóteles (384-322) ou a pluralidade do ser como base da retórica. In: MEYER, M.; CARRILHO, M. M.; TIMMERMANS, B. História da Retórica. Lisboa: Temas e Debates, 2002. p. 43-58.

KERFERD, G. B. O Movimento Sofista. São Paulo: Loyola, 1999.

LEMGRUBER, M. S.; OLIVEIRA, R. J. de. Argumentação e Educação: da ágora às nuvens. In: LEMGRUBER, M. S.; OLIVEIRA, R. J. de (Orgs.). Teoria da argumentação e educação. Juiz de Fora: Editora UFJF, 2011. p. 23-56.

MEIRELES, C. Ou isto ou aquilo. São Paulo: Global Editora, 2014.

MEYER, M. A problematologia como chave para a unidade da retórica. In: MEYER, M.; CARRILHO, M. M.; TIMMERMANS, B. História da Retórica. Lisboa: Temas e Debates, 2002. p. 265-298.

MEYER, M. A retórica. Tradução de Marly N. Peres. São Paulo: Ática, 2007.

OLIVEIRA, R. J. de. Argumentação e Educação: as contribuições de Chaïm Perelman. Curitiba: CRV, 2016.

OLIVEIRA, R. J. de. Ética na escola: por uma abordagem argumentativa. Revista Educação, Porto Alegre, v. 37, n. 3, p. 454-462, set./dez. 2014.

OLIVEIRA, R. J. de. A Nova Retórica, a Problematologia e a Educação. In: LEMGRUBER, M. S.; OLIVEIRA, R. J. de (Orgs.). Teoria da argumentação e educação. Juiz de Fora: Editora UFJF, 2011a, p. 91-106.

OLIVEIRA, R. J. de. A ética no discurso pedagógico da atualidade. Niterói: Intertexto, 2011b.

OLIVEIRA, R. J. de. Modernidade e escola: contribuições da retórica para pensar a ação educativa. In: COLÓQUIO FRANCO BRASILEIRO DE FILOSOFIA DA EDUCAÇÃO, 4., 2008, Rio de Janeiro. Anais... Rio de Janeiro: UERJ, 2008. p. 1-14.

PERELMAN, C. Retóricas. 2. ed. São Paulo: Martins Fontes, 2004.

PERELMAN, C.; OLBRECHTS-TYTECA, L. Tratado da argumentação: a Nova Retórica. 6. ed. São Paulo: Martins Fontes, 2005.

REBOUL, O. Introdução à retórica. 2. ed. São Paulo: Martins Fontes, 2004.

Texto recebido em 17 de maio de 2017. Texto aprovado em 03 de dezembro de 2017. 